Revista Destaques Acadêmicos, Lajeado, v. 10, n. 2, 2018. ISSN 2176-3070

DOI: http://dx.doi.org/10.22410/issn.2176-3070.v10i2a2018.1569

http://www.univates.br/revistas

\title{
A DELIMITAÇÃO DO ESPAÇO RURAL EM PORTO ALEGRE: TERRITÓRIO, REGIÃO E DESENVOLVIMENTO
}

\author{
Melissa Heberle ${ }^{1}$, Luciana Turatti² ${ }^{2}$ Júlia Elisabete Barden ${ }^{3}$
}

Resumo: O presente artigo apresenta uma análise do projeto aprovado que recria a zona rural de Porto Alegre. O aporte teórico para o estudo lança mão, principalmente, dos conceitos de região, território e espaço rural. São apresentados os aspectos positivos e negativos do estudo de caso, a partir das diferentes visões suscitadas. Por fim, a discussão se apoia em reflexões sobre temas como desenvolvimento, desenvolvimento sustentável e desenvolvimento humano.

Palavras-chave: Lugar. Espaço rural. Qualidade de vida.

\section{INTRODUÇÃO: A ZONA RURAL DE PORTO ALEGRE}

Dentre as capitais brasileiras, Porto Alegre ocupa a segunda posição em área rural segundo o Instituto Brasileiro de Geografia e Estatística (IBGE), com doze mil hectares localizados nas zonas sul e extremo sul da cidade (O SUL, 2015). Nesse contexto, a aprovação, em 2015, do Projeto de Lei Complementar do Executivo (PLCE) 007/14, aberto em 05/11/2014 e com último trâmite em 26/07/2016 (CÂMARA MUNICIPAL DE PORTO ALEGRE, 2017), restaura a delimitação de uma zona rural extinta há quase vinte anos na capital gaúcha.

Em 1979, quando criada pelo primeiro Plano Diretor de Desenvolvimento Urbano, a zona rural de Porto Alegre correspondia a cerca de $140 \mathrm{~km}^{2}$. Todavia, com a vigência do novo Plano Diretor de Desenvolvimento Urbano Ambiental, em 1999, a zona foi extinta. "Com isso, propriedades rurais passam a fazer

1 Licenciada e mestre em Letras, doutoranda do Programa de Pós-Graduação em Ambiente e Desenvolvimento da UNIVATES. Professora do IFSul Câmpus Lajeado. melissaheberle@ifsul.edu.br

2 Graduada em Ciências Jurídicas e Sociais, mestre e doutora em Direito. Professora do Programa de Pós-Graduação em Ambiente e Desenvolvimento e do Programa de Pós-Graduação em Sistemas Ambientais Sustentáveis, ambos da UNIVATES. lucianat@univates.br

3 Graduada em Ciências Econômicas, mestre em Economia Rural e doutora em Economia. Professora do Programa de Pós-Graduação em Ambiente e Desenvolvimento e do Programa de Pós-Graduação em Biotecnologia, ambos da UNIVATES. jbarden@univates.br 
parte da área urbana, independentemente da localização. O conceito de zona rural da cidade foi substituído pela chamada 'rururbana'"' (SORDI, 2015).

Com a atual aprovação do projeto, a área de produção primária passa a ser denominada de Zona Rural, abrangendo, aproximadamente, " $40 \mathrm{~km}^{2}$ do Extremo-Sul, voltados à agricultura, à pecuária e ao extrativismo". O projetou dividiu opiniões e gerou debates entre produtores rurais, pesquisadores, ambientalistas e construtores civis, especialmente no que diz respeito ao tamanho da nova zona rural, que representava $30 \%$ da área de Porto Alegre antes de sua extinção em 1999 e agora representará pouco mais de 8\% do município (SORDI, 2015).

\section{REGIÃO, TERRITÓRIO E ESPAÇO RURAL: ALGUNS CONCEITOS}

Nesta seção serão apresentados os conceitos de região, território e espaço rural, no que tange à sua relevância ao presente estudo. Nesse sentido, Solórzano et al (2009) destacam a importância do conceito de território para a interpretação dos "processos de transformação social do espaço":

O território pode ser compreendido como o espaço onde se projetou o trabalho, o qual revela as relações marcadas pelo poder (RAFFESTIN, 1993). Portanto, fundamentalmente, o território é um espaço definido e delimitado por e a partir de relações de poder (SOUZA, 2003). Ao mesmo tempo, o território pode ser compreendido como o espaço concreto em si, com os seus atributos naturais, que é apropriado, ou ocupado, por um grupo social, que, por sua vez, alicerça raízes no espaço e possui uma identidade com ele (SOUZA, 2003). Milton Santos (2001) considera que o território não é apenas um substrato material, mas, igualmente, uma identidade, um sentimento de pertencer a um dado espaço. Neste sentido, o território é a base das trocas materiais, do trabalho, da residência, dentre outros espaços (SOLÓRZANO ET AL, 2009, p. 53).

Assim, os autores ilustram "a importância da relação do ser humano com o espaço, gerando uma intrínseca relação de uso e troca com o meio físico" (SOLÓRZANO ET AL, 2009, p. 53).

A região, por sua vez, na perspectiva da ecologia histórica, "é uma unidade que pode ser reconhecida em uma dada escala devido à sua distinção espacial e temporal e à sua interação com outras unidades" (CRUMLEY apud SOLÓRZANO ET AL, 2009, p.55).

Solórzano et al (2009, p. 55) ainda pontuam também a relevância de a região "apresentar uma homogeneidade perceptível, que explicite as suas relações temporais, como as suas conexões com o passado e o futuro, e espaciais, como as suas conexões com outras unidades em escalas diversas". 
Nesse contexto, Haesbaert (2010) complementa que a "identidade de uma região"

se refere às "características de natureza, cultura e dos habitantes que distinguem ou, de fato, podem ser usadas nos discursos da ciência, da política, do ativismo cultural ou da economia para distinguir a região frente às demais", através de classificações que excluem determinados elementos e incluem outros, expressando assim o "poder de delimitar, nomear e simbolizar o espaço e grupos de pessoas" (PAASI, 2002b:140). Por outro lado, a "identidade" ou "consciência" regional - ou, se quisermos, também, num certo sentido, regionalidade - envolve a identificação dos habitantes com sua região, tanto dentro quanto fora dela. Participam na sua construção ativistas sociais, instituições e organizações etc (HAESBAERT, 2010, p. 19).

Para Souza e Brandenburg (2010, p. 51), “o rural brasileiro, que era visto por alguns setores da sociedade como sinônimo de atraso e de problemas, vem mudando esse "status", passando a ser identificado como portador de soluções". Também segundo os autores, o rural, antes considerado "espaço privado", passa a ser visto como "espaço público", vivenciando uma multiplicação de suas funções junto à sociedade, tais como a preservação da paisagem, do ambiente e do patrimônio social e cultural, além do desenvolvimento de atividades de lazer e de turismo.

Os mesmos autores, estudando o caso da região metropolitana de Curitiba, trazem o conceito de um "rural metropolitano", caracterizando o mundo rural "como um lugar (ou lugares) no qual os elementos constitutivos da dinâmica social se exercem de forma original, independente dele ser mais ou menos integrado à dinâmica urbana ou até mesmo alheio a ela" (SOUZA; BRANDENBURG, 2010, p. 53).

$\mathrm{Na}$ expressão "rural metropolitano" é o primeiro que se quer evidenciar e não o segundo. Em outras palavras, o "rural" é a categoria central de análise enquanto que o "metropolitano" o adjetiva, é o complemento que trata de diferenciá-lo dentro do rol das muitas formas de expressão do rural brasileiro. (...) Note-se que a adjetivação utilizada não é incompatível com as abordagens teóricas citadas anteriormente (novas ruralidades, pluriatividade ou multifuncionalidade da agricultura) e nem se pretende como tal. Mas, o rural metropolitano é, antes de tudo, um recurso capaz de trazer elementos para a compreensão da dinâmica regional em seu conjunto, conferindo ao espaço rural a "visibilidade" e também o entendimento da sua forma particular de utilização do espaço e de vida social (SOUZA; BRANDENBURG, 2010, p. 54). 
Assim, com a modernização, as transformações técnicas, que focavam a produção agrícola sem considerar o espaço rural em sentido amplo, "buscaram dissociar a natureza do processo de produção", uma vez que "a natureza sempre poderia ser corrigida de forma a se ajustar às exigências da produção". Contudo, é na década de 80 que ocorre a "reinserção ou o retorno da natureza na questão da produção agrícola", observando-se um movimento contrário ao observado na modernização agrícola identificado como "desterritorialização" (SOUZA; BRANDENBURG, 2010, p. 55).

Nesse contexto, segundo os autores, passa a se materializar "um processo de territorialização da produção" que

recoloca a natureza como mediadora das relações sociais, inclusive relações de produção, evidenciando as qualidades de cada região, de cada território, buscando reforçar as identidades regionais e territoriais. Trata-se de uma representação mais plural da natureza que traz consigo alguns elementos inéditos e que, ao ganhar visibilidade, muda profundamente o olhar que a sociedade lança sobre o mundo rural (SOUZA; BRANDENBURG, 2010, p. 55).

Diante desse contexto, ocorre "tanto uma nova qualificação dos espaços (regiões, territórios) quanto um processo de complexificação das suas funções com base nos seus diferentes usos" (SOUZA; BRANDENBURG, 2010, p. 55, grifo nosso).

\section{ESPAÇO RURAL: ASPECTOS POSITIVOS E NEGATIVOS}

A aprovação do PLCE 007/14 que restaura a delimitação da zona rural extinta em 1999 em Porto Alegre suscitou distintos posicionamentos. No caso específico de pesquisadores e ambientalistas, o principal ponto negativo apontado foi a contemplação, no projeto, de somente "áreas de produção, deixando de fora regiões de proteção ambiental". Neste sentido, conforme a diretora do Departamento de Meio Ambiente e Licenciamento da Universidade Federal do Rio Grande do Sul (UFRGS), Andrea Longuercio, "os recortes prejudicam uma das principais funções de uma zona rural, que é a de ser um grande cinturão verde na cidade". Segundo ela, o projeto "poderia ser melhorado ao tentar não deixar ambientes que devem ser protegidos expostos à especulação imobiliária" (SORDI, 2015).

O Documentário Cinturão Verde de Porto Alegre: Território em Disputa (2014) retrata bem esse cenário:

Porto Alegre está em disputa. De um lado, construtoras imobiliárias, que enxergam a cidade como uma mercadoria e tem intenção de transformar todos os espaços possíveis em lucro. Do outro, cidadãos que veem a metrópole como um lugar para se viver, onde se acolha dignamente todas as pessoas, tenham dinheiro ou não. Onde se 
respeite a biodiversidade local, suas matas e ambientes naturais, seus animais silvestres e sua produção de alimentos (AMIGOS DA TERRA BRASIL, 2014).

Dessa forma, um projeto de cidade está sendo "imposto" pela iniciativa privada. "Uma ofensiva da construção civil sobre esta região, sem necessidade e sem planejamento, já que existem 48 mil imóveis desocupados, para uma demanda de 38 mil famílias", dados do IBGE (AMIGOS DA TERRA BRASIL, 2014).

Diante dessa situação, o produtor de hortaliças orgânicas Vasco Machado tem medo de "perder a sensação de segurança" da vida no campo, devido aos "empreendimentos habitacionais do programa Minha Casa Minha Vida, o avanço de condomínios de luxo e de ocupações irregulares" (SORDI, 2015).

Nas obras dos residenciais luxuosos, a terra fica arrasada, com alteração total da topografia e da paisagem, e as áreas nativas que restam são cercadas, sem se comunicar com o entorno, afetando a flora, a fauna e a população que ali já vive. Entre esses habitantes, estão aldeias das três etnias indígenas que vivem no Estado. Os guarani, os Caingangue e os Charrua estão em pequenas comunidades que se mantém principalmente com o artesanato, e a matéria-prima que usam vem boa parte das matas da região. Atualmente, eles circulam livremente pelas propriedades rurais, mas a transformação destas áreas em condomínios de luxo ameaça esta dinâmica, sua forma de vida e seu sustento (AMIGOS DA TERRA BRASIL, 2014).

Já os condomínios populares do programa Minha Casa Minha Vida atraem as comunidades "expulsas do centro pelas obras viárias e pela especulação imobiliária, que as força a migrarem para áreas mais periféricas" que, em vários casos, não têm posto de saúde, creche ou escola, oportunidade de trabalho, nem oferta de transporte adequada. Assim, moram na Zona Sul "por falta de opção ou por imposição", com a violação ou o abandono de seus direitos (AMIGOS DA TERRA BRASIL, 2014).

Para o presidente da Comissão Especial que avaliou o projeto, vereador Cassio Trogildo, ainda "é preciso rever o fato de a zona estipulada não abranger todos os produtores primários da região", pois mais de duzentos proprietários ficam fora da área delimitada (SORDI, 2015).

Por outro lado, o titular da Secretaria da Produção, Indústria e Comércio, Humberto Goulart, pondera que "a delimitação da zona rural possibilitará a implantação de agroindústrias familiares de transformação, (...) os pequenos produtores terão direito a linhas de crédito especiais para atividades primárias e a políticas que fomentam a agricultura" (O SUL, 2015). 
Os ambientes ficam mais protegidos, o que garante um clima melhor para a região central e maior circulação de ar. Com projetos como esse, é possível transformar Porto Alegre em um grande polo de alimentos orgânicos, contribuindo de modo significativo para a economia (SORDI, 2015).

Além desses fatores positivos, o secretário Goulart menciona a manutenção da flora e fauna, da sustentabilidade ambiental e da tradição cultural, histórica e econômica da região sul de Porto Alegre (O SUL, 2015).

É preciso entender esta região como já cumprindo um papel, uma função socioambiental que ela já tem. A região sul de Porto Alegre precisa ser valorizada pela sua produção de alimentos, pelos benefícios que traz para o clima, pela preservação dos recursos hídricos, pela possibilidade de manter a cultura de povos tradicionais, com as quais a sociedade tem dívida e compromisso. Perder este potencial dentro do próprio território da cidade é mais do que negligência, é um crime (AMIGOS DA TERRA BRASIL, 2014).

Seguindo a mesma linha de pensamento, o diretor da Divisão de Fomento Agropecuário, Antonio Bertaco, afirma que a lei também "habilitará os produtores a receberem o licenciamento ambiental de atividades envolvendo a criação de animais" (O SUL, 2015).

$\mathrm{O}$ vice-diretor do Sindicato das Indústrias de Construção Civil do Rio Grande do Sul, Sergio Junior, considera o projeto racional e defende que este

respeita as construções existentes, contempla áreas da produção primária e não interfere na demanda por novos empreendimentos na região; (...) deixa espaço para a produção rural e contempla a demanda que existe da população urbana, de morar em casas com pátio, em construções horizontais (SORDI, 2015).

Por fim, para o presidente do Sindicato Rural da Capital, Cléber Vieira, a recriação da zona rural é uma antiga reivindicação, uma vez que o produtor não consegue empréstimos por não ter "legitimidade legal, por não produzir em uma zona rural". Na esteira do que afirma o presidente, Ingrid Barros, professora da UFRGS, menciona que a lei "deve fortalecer feiras e mercados locais, beneficiando agricultores e consumidores, (...) os produtores poderão reduzir custos com frete, as perdas pós-colheita" (SORDI, 2015).

\section{CONCLUSÕES SOBRE O DESENVOLVIMENTO: ALGUNS CAMINHOS}

O geógrafo Porto-Gonçalves (2004) caracteriza o ambiente como local de disputas de espaço e apresenta o conceito de "des - envolver", com o sentido de não envolver, tirar a autonomia, desrespeitar o outro, colonizar. 
Nesse contexto, os aportes teóricos que discutem as ruralidades, a pluriatividade e a multifuncionalidade da agricultura "vêm sendo de grande valia para dar visibilidade e reposicionar o heterogêneo universo rural brasileiro ao lugar que lhe cabe no tema do desenvolvimento" e "todos perpassam a ideia de que as novas demandas sociais impõem uma série de conflitos à gestão do espaço rural" (SOUZA E BRANDENBURG, 2010, p. 53-54).

Os conflitos podem ter diferentes causas, como a urbanização, a falta de planejamento, a negação do outro, o não acesso a direitos fundamentais, a desconsideração de questões culturais e regionais, a tentativa de usurpação do território, entre outras. Para Souza e Branderburg (2010) embora se reconheça a importância do rural regional, ainda são poucas as pesquisas sobre este espaço, bem como as políticas públicas relacionadas a ele, tornando-o invisível no processo do planejamento das cidades, que é caracterizado por um viés urbano.

Em meio a isso, surge o questionamento sobre como trabalhar com as diferentes racionalidades (econômica, social, cultural, ambiental etc.), e como mediar os conflitos. Assim, permanece um questionamento essencial que diz respeito ao conhecimento de "como as políticas públicas devem se "equiparar" (ou se ancorar científica e teoricamente) e se legitimar para comportar esta complexidade e os conflitos de interesses resultantes dessa nova visão da sociedade sobre os espaços rurais" (SOUZA E BRANDENBURG, 2010, p.62).

Nesse cenário, os autores observam a alteração de foco do desenvolvimento agrícola para o desenvolvimento rural sustentável. "Novos desafios são colocados tanto para a compreensão das complexas funções do rural e dos territórios quanto para a formulação das políticas públicas que deveriam dar conta de toda esta complexidade" (SOUZA E BRANDENBURG, 2010, p.56). Assim,

a mudança de visão sobre o espaço rural que o coloca não apenas como espaço de produção de matérias primas, mas também como uma paisagem, um espaço cultural e simbólico, envolve uma profunda inversão de prioridades na gestão daquilo que "não é cidade" (HERVIEU apud SOUZA E BRANDENBURG, 2010, p. 58).

Nesse contexto, a Agenda 2030 para o Desenvolvimento Sustentável apresenta objetivos e metas relacionados ao desenvolvimento sustentável que são universais, considerando o legado deixado pelos Objetivos de Desenvolvimento do Milênio, visando avançar nos pontos não atingidos. Busca "assegurar os direitos humanos de todos", por meio de objetivos indivisíveis e integrados que enfocam "as três dimensões do desenvolvimento sustentável": econômica, social e ambiental.

Esses objetivos e metas "estimularão a ação em áreas de importância crucial para a humanidade e para o planeta nos próximos 15 anos", como é o caso da área intitulada Pessoas: "Estamos determinados a acabar com a 
pobreza e a fome, em todas as suas formas e dimensões, e garantir que todos os seres humanos possam realizar o seu potencial em matéria de dignidade e igualdade, em um ambiente sustentável" (BRASIL, 2016).

Nesse sentido, Mazzarino (2012) contribui ao afirmar que

o debate sobre os temas socioambientais têm a força de poder desencadear a criação de capital social pela natureza da sua problemática: atinge a todos os cidadãos de forma global. $\mathrm{O}$ debate público em torno desses temas pode gerar: a partilha de valores relativos à cidadania ambiental, a percepção da interdependência entre todas as formas de vida, a formação de laços de pertencimento entre as pessoas e entre elas e o meio, a criação de objetivos comuns para melhoria das condições socioambientais (MAZZARINO, 2012, p. 92, grifos nossos).

Assim, segundo Zhouri e Oliveira (2010, p. 445, grifos nossos), “a defesa do lugar, do enraizamento e da memória destaca a procura por autodeterminação, a fuga da sujeição aos movimentos hegemônicos do capital e a reapropriação da capacidade de definir seu próprio destino" das populações. Dessa forma, esses movimentos são contrários à atopia ao insistir "em nomear os lugares, em definir-lhes seus usos legítimos, vinculando a sua existência à trajetória desses grupos".

Ainda de acordo com as autoras, "na perspectiva dos chamados "atingidos" pelos projetos de desenvolvimento, o lugar é referência para a construção de suas identidades políticas, ele significa, sobretudo, a retomada do controle do seu próprio destino" (ZHOURI; OLIVEIRA, 2010, p. 457).

O Programa das Nações Unidas para o Desenvolvimento no Brasil (2017) apresenta o importante conceito de desenvolvimento humano, que pode ser caracterizado como o "processo de ampliação das escolhas das pessoas para que elas tenham capacidades e oportunidades para serem aquilo que desejam ser". Dessa forma, "diferentemente da perspectiva do crescimento econômico, que vê o bem-estar de uma sociedade apenas pelos recursos ou pela renda" gerada, essa abordagem "procura olhar diretamente para as pessoas, suas oportunidades e capacidades":

A renda é importante, mas como um dos meios do desenvolvimento e não como seu fim. É uma mudança de perspectiva: com o desenvolvimento humano, o foco é transferido do crescimento econômico, ou da renda, para o ser humano (PROGRAMA DAS NAÇÕES UNIDAS PARA O DESENVOLVIMENTO NO BRASIL, 2017).

Além disso, a ideia de desenvolvimento humano "também parte do pressuposto de que para aferir o avanço na qualidade de vida de uma população 
é preciso ir além do viés puramente econômico e considerar outras características sociais, culturais e políticas que influenciam a qualidade da vida humana (PROGRAMA DAS NAÇÕES UNIDAS PARA O DESENVOLVIMENTO NO BRASIL, 2017, grifo nosso)".

A partir das ideias apresentadas, é preciso se refletir, não só no caso do PLCE 007/14 de Porto Alegre, mas podendo ser estendido a outros, sobre a importância de planejamento por parte do município, responsável pela razão pública, considerando os diferentes interesses envolvidos e promovendo o envolvimento de toda a população no debate das questões coletivas. Afinal, é preciso se considerar as pessoas, suas histórias, identidades, e sentimentos de pertencimento ao lugar.

Enfim, uma gestão mais sustentável e humana do território envolve a consideração das diferentes racionalidades, dos múltiplos atores, dos possíveis conflitos gerados e a adoção de metodologias de governança.

\section{REFERÊNCIAS}

AMIGOS DA TERRA BRASIL. Cinturão Verde de Porto Alegre: Território em Disputa. Porto Alegre, 2014. Disponível em: < https://amigosdaterrabrasil.wordpress. com/2014/12/08/ cinturao-verde-de-porto-alegre-territorio-em-disputa $>$. Acesso em: 13 jan. 2017.

BRASIL.Transformando Nosso Mundo: a Agenda 2030 para o Desenvolvimento Sustentável. 2016. Disponível em: <http://www.br.undp.org/content/dam/brazil/ docs/agenda2030/undp-br-Agenda2030-completo-pt-br-2016.pdf >. Acesso em 10 jan. 2017.

CÂMARA MUNICIPAL DE PORTO ALEGRE. Disponível em: < http://www. camarapoa.rs.gov.br/processos/123668>. Acesso em: 20 fev. 2017.

Documentário Cinturão Verde de Porto Alegre: Território em Disputa. 2014.

Disponível em: <https://www.youtube.com/watch?v=xXPW24DWqDM>. Acesso em: 13 jan. 2017.

HAESBAERT, Rogério. Região, regionalização e regionalidade: questões contemporâneas. Antares: Caxias do Sul, n.3, p. 2-24, 2010.

MAZZARINO, Jane Márcia. O campo jornalístico e a construção do capital comunicacional socioambiental. RCA. Revista de Ciências Ambientais (UniLASALLE), v. 6, p. 81-94, 2012.

O SUL. Porto Alegre voltará a ter uma zona rural. Porto Alegre: Rede Pampa de Comunicação, 2015. Disponível em: < http:/ /www.osul.com.br/porto-alegre-voltaraa-ter-uma-zona-rural>. Acesso em: 13 jan. 2017. 
PORTO-GONÇALVES, Carlos. Walter. O desafio ambiental. Rio de Janeiro: Record, 2004.

PROGRAMA DAS NAÇÕES UNIDAS PARA O DESENVOLVIMENTO NO BRASIL. O que é Desenvolvimento Humano. Disponível em: <http:/ / www.br.undp.org/ content/brazil/pt/home/idh0/conceitos/o-que-e-desenvolvimento-humano.html>. Acesso em: 20 fev. 2017.

SOLÓRZANO, A.; OLIVEIRA, R.R. de.; GUEDES-BRUNI, Rejan Rodrigues. Geografia, História e Ecologia: criando pontes para a interpretação da paisagem. Ambiente \& Sociedade: Campinas, v. XII, n. 1, p.49-66, 2009.

SORDI, Jaqueline. Projeto prevê volta da delimitação de Zona Rural em Porto Alegre. Porto Alegre: Zero Hora, 2015. Disponível em: <http:/ / zh.clicrbs.com.br/rs / porto-alegre/noticia/2015/06/projeto-preve-volta-da-delimitacao-de-zona-rural-emporto-alegre-4783141.html>. Acesso em: 13 jan. 2017.

SOUZA, O. T. de.; BRANDENBURG, A. A quem pertence o espaço rural? As mudanças na relação sociedade/natureza e o surgimento da dimensão pública do espaço rural. Ambiente \& Sociedade: Campinas, v. XIII, n. 1, p.51-64, 2010.

ZHOURI, A.; OLIVEIRA, R. Quando o lugar resiste ao espaço. Colonialidade, modernidade e processos de territorialização. In: Z HOURI, A. LASCHEFKI, K.(Orgs.). Desenvolvimento e Conflitos Ambientais. Belo Horizonte: UFMG, 2010. $484 \mathrm{p}$. 